\title{
Responses of photosynthetic apparatus in sunflower cultivars to combined drought and salt stress
}

\author{
M. UMAR ${ }^{*}$, Z. UDDIN**, and Z.S. SIDDIQUI*,+ \\ Stress Physiology Phenomic Centre, Department of Botany, University of Karachi, 75270 Karachi, Pakistan* \\ Department of Physics, University of Karachi, 75270 Karachi, Pakistan**
}

\begin{abstract}
Response of photosynthetic apparatus in some sunflower cultivars, i.e., S.28111, Hysun-33, Hysun-39, and SF0049, to salt, drought, and combined stresses were studied. The combined stress caused severe damage to photosynthetic apparatus as compared to single stress. The maximum quantum yield of PSII, phenomenological fluxes, plastoquinone pool size, performance indexes, and driving force of absorption were greatly affected by the combined stress. Among the cultivars, the combined stress produced synergistic effect (greater damage) in Hysun-33 and cross-tolerance (lesser damage) in S.28111. Similarly, concerning the ion imbalance, S.28111 and SF0049 showed lower $\mathrm{Na}^{+}$and $\mathrm{Cl}^{-}$concentrations with lesser electrolyte leakage as compared to Hysun-33 and Hysun-39 under salt and combined stress. Results revealed that the disturbance in photosynthetic performance could be easily determined using JIP test by measuring chlorophyll $a$ fluorescence. This information can be useful for the screening of oil-seed crop plants having better photosynthetic performance under salinized and desertified conditions.
\end{abstract}

Additional key words: electron transport rate; malondialdehyde; nonphotochemical quenching; OJIP transient.

\section{Introduction}

Sunflower (Helianthus annuus L.) is one of the largest and most important oil-seed crops for its edible oil, food for animals, and appetizers in human diet. It has higher unsaturated fatty acid contents and lesser amount of cholesterol. Almost 33-million-ton oil seed production is contributed by sunflower which is $8.5 \%$ of the total world production (Saensee et al. 2012). This crop is considered as moderately salt-tolerant and thus its production is still expanding. However, the growth and seed production are not high enough due to adverse agronomic and environmental conditions. The possible solution for higher abiotic stress tolerance is the selection of suitable sunflower cultivars that can survive in high soil toxicity, improve their water-use efficiency, and produce higher yields under abiotic stress.

Abiotic stresses are the major growth restricting factors for the crop production in the world (Wang et al. 2003). More than $30 \%$ productive land has faced yield reduction due to drought conditions. Furthermore, the area affected by salinity and drought is still expanding in the world. Drought stress alters the plant's growth rate by disturbing its physiological processes and biochemical activities (Iqbal et al. 2008, Umar and Siddiqui 2018). Drought or salt stress tolerance varies among the cultivars of the same species. The most effective approach to overcome salt and drought stress is the development of tolerant crop cultivars. Hence, it is dire need to identify the genetic resources with a greater tolerance and to understand the physiological

Received 5 July 2018, accepted 6 February 2019.

${ }^{+}$Corresponding author; e-mail: zaminss@uok.edu.pk

Abbreviations: ABS/RC - apparent antenna size of active PSII RC; Area - area over the fluorescence curve between $\mathrm{F}_{0}$ and $\mathrm{F}_{\mathrm{m}}$; $\mathrm{DF}_{\mathrm{ABS}}-$ driving force on absorption basis; $\mathrm{DI}_{0} / \mathrm{RC}$ - effective dissipation of energy in active $\mathrm{RC} ; \mathrm{ET}_{0} / \mathrm{RC}$ - electron transport per active reaction center; $F_{0}$ - minimum fluorescence; $F_{0} / F_{v}$ - efficiency of water-splitting complex; $F_{0} / F_{m}$ - quantum yield baseline; $F_{m}-$ maximum fluorescence; $\mathrm{F}_{\mathrm{m}} / \mathrm{F}_{0}$ - electron transport rate through PSII; $\mathrm{F}_{\mathrm{v}} / \mathrm{F}_{0}$ - size and number of active reaction centers of photosynthetic apparatus; $\mathrm{F}_{\mathrm{v}} / \mathrm{F}_{\mathrm{m}}$ - maximum quantum yield of PSII; $J$ - linear electron transport rate; MDA - malondialdehyde; NPQ - nonphotochemical quenching; $\mathrm{PI}_{\mathrm{ABS}}$ - performance index on absorption basis; $\mathrm{PI}_{\mathrm{CS}}$ - performance index on cross-section basis; $\mathrm{PI}_{\text {tot }}-$ total performance index; $\mathrm{q}_{\mathrm{N}}$ - nonphotochemical quenching coefficient; $\mathrm{q}_{\mathrm{P}}$ - photochemical quenching; RC/ABS - density of reaction centers on chlorophyll basis; $\mathrm{RC} / \mathrm{CS}_{\mathrm{m}}$ - amount of active reaction centers per excited cross section; $\mathrm{TR}_{0} / \mathrm{DI}_{0}$ - ratio of trapping and dissipation fluxes; $\mathrm{TR}_{0} / \mathrm{RC}$ - maximal trapping rate of absorbed photons in $\mathrm{RC} ; \delta_{\mathrm{R} 0}$ or $\mathrm{RE}_{0} / \mathrm{ET}_{0}$ - probability that an electron is transported from reduced PQ to electron acceptor side of PSI; $\Delta \mathrm{V}_{\mathrm{IP}}$ - amplitude of the relative variable fluorescence of the I-to-P-rise; $\Phi_{\mathrm{PSII}}-$ efficiency of PSII or quantum yield of PSII; $\phi_{\mathrm{R} 0}-$ quantum yield for reduction of the end electron acceptors at the PSI acceptor side (RE); $\psi_{0}-$ yield of electron transport per trapped excitation or probability with which a PSII trapped electron is transferred from reduced $Q_{A}$ to $Q_{B}$. Acknowledgements: Authors are grateful to the Department of Botany, University of Karachi for support of the study. We are also thankful to Seed Certification Department, Government of Pakistan, and FMC corporation, Pakistan, for providing seeds. The financial support from NCGC (Next-Generation BioGreen21 Program No. PJ01131902 and PJ01123204), South Korea, is also acknowledged. 
mechanisms of tolerant plants.

PSII functionality and overall photosynthetic performance of crop plants can be evaluated by chlorophyll $a$ fluorescence, which is known to be the most reliable technique that reflects the physiological mechanism of crop cultivars under stressful environments (Stirbet and Govindjee 2011, Yan et al. 2013, Dąbrowski et al. 2017). Salt and drought stresses restrict water uptake through roots and thus limit the photosynthesis via stomatal and nonstomatal limitations. Koyro et al. (2013) reported that higher amount of $\mathrm{NaCl}$ can affect the photosynthetic enzymes and oxygen-evolving complex of PSII may also dissociate or become inactivated. To investigate the effects of abiotic stresses on photosynthesis, chlorophyll (Chl) $a$ fluorescence kinetics can be a useful tool. Kalaji et al. (2011) reported that the minimum fluorescence $\left(\mathrm{F}_{0}\right)$, maximum florescence $\left(\mathrm{F}_{\mathrm{m}}\right)$, size and number of active reaction center of photosynthetic apparatus $\left(\mathrm{F}_{\mathrm{v}} / \mathrm{F}_{0}\right)$, and performance index on absorption basis $\left(\mathrm{PI}_{\mathrm{ABS}}\right)$ are the most affected parameters under abiotic stress which not only depend on the efficiency but are also responsible for energy transfer and primary photochemistry of the plants. Photochemistry is initiated when the pigments in the antenna complex of PSI and PSII capture incident photons. The absorbed energy in thylakoid membrane leads to the electron transport from water to $\mathrm{NADP}^{+}$. These electrons are sequentially transported through primary electron acceptor of PSII (pheophytin), quinone $A\left(Q_{A}\right)$, quinone $\mathrm{B}\left(\mathrm{Q}_{\mathrm{B}}\right)$, plastoquinone $(\mathrm{PQ})$ pool, cytochrome $b_{6} f$, plastocyanin (PC), and then reach to PSI acceptor side

Disturbance in electron journey at any point during the electron transport chain can reduce the photosynthetic efficiency. It was observed that abiotic stress like salinity and drought impaired the efficiency of PSI and PSII (Gao et al. 2016). Therefore, it was assumed that different sites of photosynthetic electron transport chain might have variable responses against single or in combination of salt and drought stresses. In this regard, Chl fluorescence can be a useful tool to investigate alterations in electron transport chain specifically at (1) PSII electron donor side, (2) transport of electron between PSII and PSI, and (3) electron acceptor side of PSI under salt and drought stress (Strasser et al. 2010, Kan et al. 2017). The literature regarding the potential capability of $\mathrm{Chl} a$ fluorescence to detect the changes in photosynthetic apparatus in sunflower is rather scarce.

JIP test offers more appropriate information about possible destiny of the absorbed energy. It may provide the evidence concerning the structure and function of the photosynthetic machinery, namely PSII activity. This test not only provides the analyses of fractions of the reaction centers but also evaluates the probability of complete energy flow in PSII components (Strasser et al. 2000, Goltsev et al. 2016). The sites of metabolic changes using a combination of both salt and drought stresses have not been studied via photosynthetic apparatus, however, individual effect of abiotic stress on photosynthetic mechanism have been studied so far.

It was expected that $\mathrm{Chl}$ fluorescence can be used for a fast assessment of cultivar acclimatization and can be helpful in management and planning (Bąba et al. 2016). The common effects of combined salt and drought stresses on growth and development of oil seed crop plants, such as sunflower and soybean, have been reported but their photochemical efficiency through $\mathrm{Chl} a$ fluorescence is not well established. Salt and drought stress may have some common effects on plants, such as reduction in growth, oxidative damage, stomatal limitation, reduction in photosynthesis, damage of cellular structure, and production of some osmolytes (Wang et al. 2003, Tang et al. 2015). Combination of these stresses on plants may have unique biochemical, photochemical or physiological responses which cannot be observed after the single stress. Information regarding the combined salt and drought stress is rather scarce. Thus, the aim of the present study was to evaluate the PSII efficiency in relation to ion accumulation in sunflower cultivars in order to identify the best genetic resources by understanding stress-responsive mechanisms under combined salt and drought stress. Further, this investigation would not only provide insights regarding the adaptability of photosynthetic apparatus of sunflower cultivars to combined salt and drought stress but also identify the cultivar that has to be used in salt- and drought-affected areas.

\section{Materials and methods}

Plant material and experimental setup: The study was performed under the greenhouse conditions (28-32/18$20^{\circ} \mathrm{C}$ of day and night temperature, under natural sunlight, and $60-70 \%$ of relative humidity) located at Stress Physiology Phenomic Center, Department of Botany, University of Karachi, Pakistan. Seeds of four Helianthus annuus cultivars, i.e., Hysun-33, Hysun-39, and S.28111, were collected from Plant Protection and Seed Certification Department, Government of Pakistan, whereas SF0049 was collected from FMC corporation, Pakistan. Hysun-33 and Hysun-39 are known as moderately drought-tolerant cultivars and were used in this study to compare the physiological performance of newly introduced cultivars, i.e., SF0049 and S.28111.

Plastic pots $(15 \times 18 \mathrm{~cm})$ were filled with $1.5 \mathrm{~kg}$ of airdried soil. The $\mathrm{pH}$ of soil was 7.5 and soil type used in this experiment was sandy loam. Seeds of each cultivar were surface-sterilized with $2 \%$ of sodium hypochloride for 5 min to avoid any contamination during germination and then five seeds in each pot were sown. At 12 DAS (days after sowing), the pots were thinned to three seedlings. Stress treatments were initiated at 30 DAS and lasted till about 44 DAS. Control plant samples were treated with tap water and the humidity of soil was kept more than $70 \%$ of water-holding capacity until harvesting. Salt stress, i.e., $175 \mathrm{mM} \mathrm{NaCl}$ concentration, was applied in regular increment in order: $75 \mathrm{mM}, 50 \mathrm{mM}$, and $50 \mathrm{mM}$ $\mathrm{NaCl}$ solution. Later, soil was kept humid retaining more than $70 \%$ of water-holding capacity throughout the experimental period. Drought stress was imposed via withholding water until soil moisture content (SMC) reached to $20 \%$ and then maintained throughout the experiment. Combined salt and drought stress was 
achieved by progressive imposition of $175 \mathrm{mM} \mathrm{NaCl}$ and then withholding water until SMC was reduced to $20 \%$. All the stress treatments were imposed for $14 \mathrm{~d}$ (initiated at 30 DAS until 44 DAS) and then plants were used for the analysis. Soil moisture and electrical conductivity were measured using soil sensor (SDI-12 Hydra Probe II, Stevens Water, USA). Experiment was organized in randomized block design having four replicates (pots) for each treatment and control. At the end of experiment (44 attached leaves at ambient temperature. The data obtained were used to calculate important parameters (Genty et al. 1989, Strasser et al. 2004, 2010; Maxwell and Johnson 2000). PSII and PSI behavior was characterized on the basis of various parameters derived from JIP test using the following formulae:

Membrane permeability and malondialdehyde (MDA) contents: Electrolyte leakage was determined using the

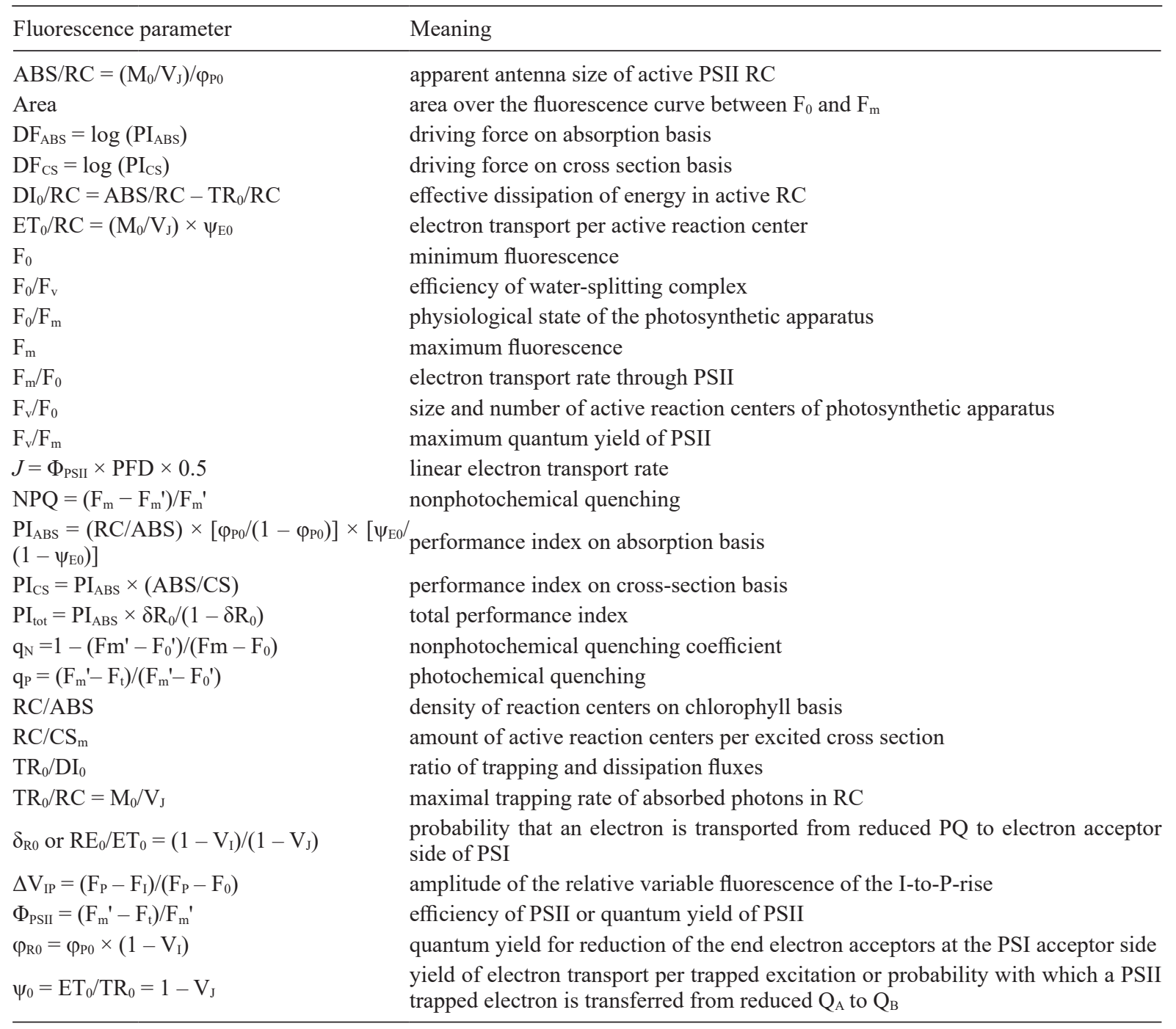

DAS), phenotypic characteristics, physiological measurements, and biochemical quantifications were investigated.

Chl fluorescence was recorded on the youngest fully expanded leaves of sunflower cultivars between 09:0011:00 h using Chl fluorescence meter $(O S-30 p+$, OptiScience, USA). The light pulse intensity used was 3,500 $\mu \mathrm{mol}\left(\right.$ photon) $\mathrm{m}^{-2} \mathrm{~s}^{-1}$. The leaves were dark-adapted for 30 min using leaf clips. The light-adapted measurements were taken during day time under natural sunlight. During measurements special care was taken to the angle of the leaf or shading. Fluorescence data were collected on method of Lutts et al. (1996) and expressed in percentage. To determine the level of lipid peroxidation in sunflower leaves at 44 DAS, the contents of thiobarbituric acidreactive substance was estimated according to the Carmak and Horst (1991) using spectrophotometer (UV-1100, Roctec, China) and the MDA contents were calculated using the extinction coefficient $\left(155 \mathrm{mM}^{-1} \mathrm{~cm}^{-1}\right)$ and then expressed as $\mathrm{mg} \mathrm{g}^{-1}$.

Ion analysis: The contents of $\mathrm{K}^{+}$and $\mathrm{Na}^{+}$were quantified using flame photometer (Jenway PFP7, UK), whereas $\mathrm{Cl}^{-}$ content was determined by titration against $0.02 \mathrm{~mol} \mathrm{~L}^{-1}$ 
silver nitrate solution using $5 \% \mathrm{~K}_{2} \mathrm{CrO}_{4}$ as indicator (Kwon et al. 2009).

Statistical analysis: Experiment was organized in randomized block design having four replicates (pots) for each treatment and control. The Chl $a$ fluorescence was measured using 12 plants from each treatment and we had four replicates for each plant $(n=48)$. Statistical analysis of the collected data was performed using Duncan's multiple range test ( $p \leq 0.05$ ) (Duncan 1955), used as post$h o c$ to analysis of variance ( $A N O V A)$ with the help of the personal computer software packages IBM SPSS Statistics (version 20). To test the differences between mean values, the Duncan's test was computed, and the resultant values were expressed on bar graph as alphabets.

\section{Results}

PSII efficiency: Salt, drought, and the combination of both stresses downregulated the photochemical efficiency of PSII. Maximum quantum yield of PSII $\left(\mathrm{F}_{\mathrm{v}} / \mathrm{F}_{\mathrm{m}}\right)$ decreased in all sunflower cultivars when exposed to combined stress as compared with control. The $\mathrm{F}_{\mathrm{v}} / \mathrm{F}_{\mathrm{m}}$ was not much affected under salt and drought stress alone (Fig. 1A). Under combined stress, the $F_{v} / F_{m}$ ratio decreased significantly in treated plants. Among the cultivars, the lowest decline was observed in S.28111 under salt, drought, and combined stresses. Similarly, the size and number of active reaction center of photosynthetic apparatus $\left(\mathrm{F}_{\mathrm{v}} / \mathrm{F}_{0}\right.$ ratio) decreased under salt and drought stress with a greater reduction noted under a combined stress (Fig. 1B). S.28111 had a higher value compared to Hysun-33, Hysun-39, and SF0049. However, $F_{v} / F_{0}$ ratio was extremely low in Hysun-33. Furthermore, a reverse trend was observed in case of $\mathrm{F}_{0} / \mathrm{F}_{\mathrm{v}}$ (Fig. 1C). Electron transport rate through PSII $\left(\mathrm{F}_{\mathrm{m}} / \mathrm{F}_{0}\right)$ decreased sharply under a combined stress as compared with control and the lowest decline was observed in Hysun-33 (Fig. 1D).

Performance index on absorption basis $\left(\mathrm{PI}_{\mathrm{ABS}}\right)$ is supposed to be a complex parameter in term of its dependency on the ratio of RC/ABS, maximum quantum yield of primary photochemistry, ratio of dissipation fluxes $\left(\mathrm{TR}_{0} / \mathrm{DI}_{0}\right)$, and efficiency of the conversion of excitation energy to electron transport $\left(\mathrm{ET}_{0} / \mathrm{TR}_{0}-\mathrm{ET}_{0}\right)$. The greater decline was observed in $\mathrm{PI}_{\mathrm{ABS}}$, when Hysun plants were subjected to combined stress (Fig. $2 A$ ). The $\mathrm{PI}_{\mathrm{ABS}}$ drastically declined in Hysun-33 and Hysun-39 as compared to S.28111 and SF0049 under salt-stressed conditions. The decline was more pronounced in both Hysun cultivars grown under drought and combined stresses. $\mathrm{DF}_{\mathrm{ABS}}$ significantly decreased under salt, drought, and combined stress as compared with control (Fig. 2B). The area above the fluorescence curve between $\mathrm{F}_{0}$ and $\mathrm{F}_{\mathrm{m}}$ was reduced in both Hysun and SF0049 as compared to S.28111 (Fig. 2D). The highest decline was recorded in Hysun-39 under combined stress. The probability that a trapped excitation transfers an electron to the electron transport chain beyond $\mathrm{Q}_{\mathrm{A}}\left(\psi_{0}\right)$ and performance index based on cross section $\left(\mathrm{PI}_{\mathrm{CS}}\right)$ decreased under stressed conditions as compared with control (Fig. 2E,F). The greater reduction in $\mathrm{PI}_{\mathrm{CS}}$ under combined

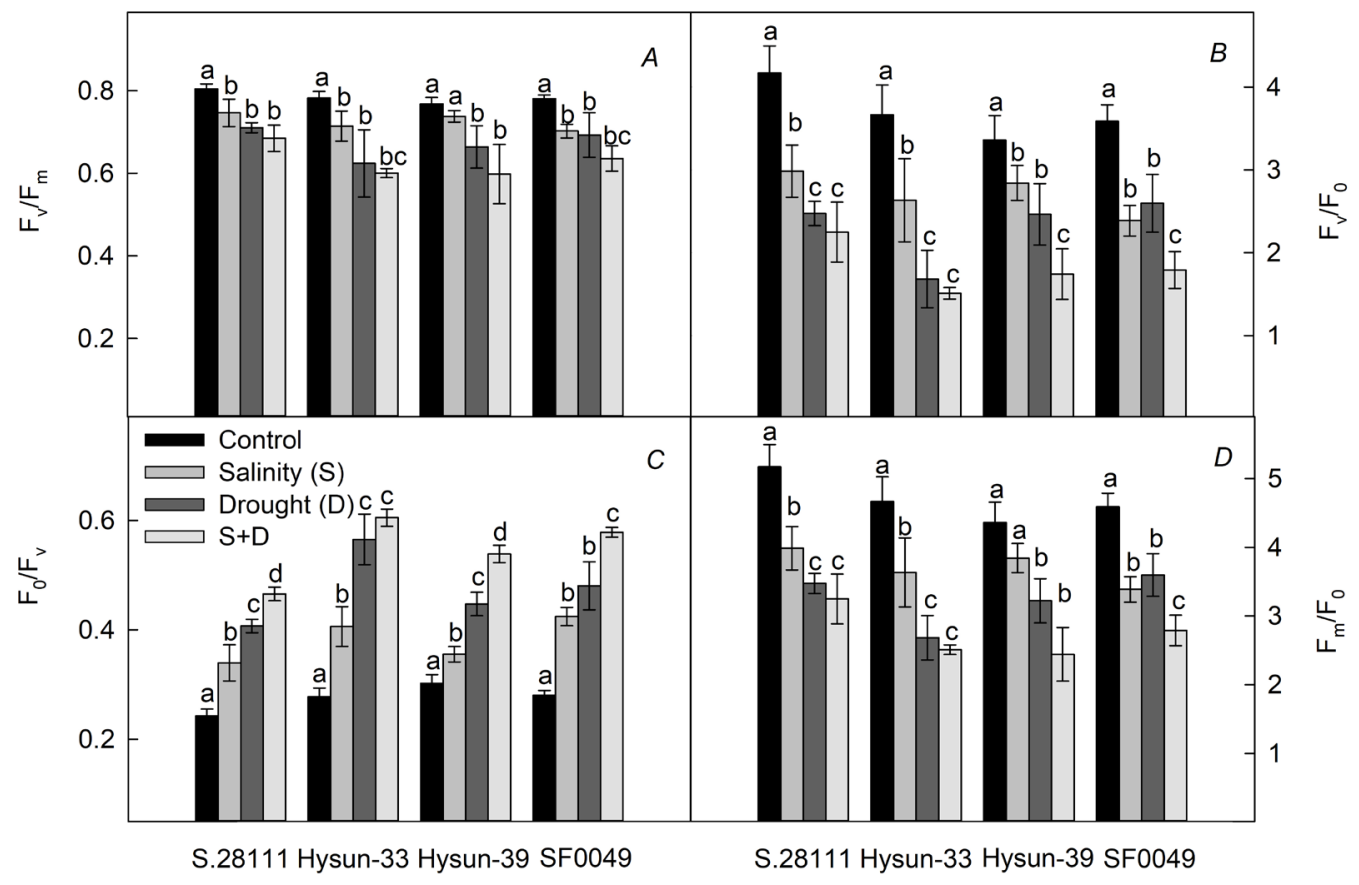

Fig. 1. Effects of salt (S), drought (D), and combined (S+D) stress on chlorophyll fluorescence parameters: $\mathrm{F}_{\mathrm{v}} / \mathrm{F}_{\mathrm{m}}(A), \mathrm{F}_{\mathrm{v}} / \mathrm{F}_{0}(B), \mathrm{F}_{0} / \mathrm{F}_{\mathrm{v}}$ $(C)$, and $\mathrm{F}_{\mathrm{m}} / \mathrm{F}_{0}(D)$ of S.28111, Hysun-33, Hysun-39, and SF0049. Vertical line on each bar represents mean standard error $( \pm)$. Values among each genotype with the same letter $(S)$ are not significantly different at $P<0.05 . \mathrm{F}_{\mathrm{v}} / \mathrm{F}_{\mathrm{m}}-$ maximum quantum yield of PSII; $\mathrm{F}_{\mathrm{v}} / \mathrm{F}_{0}$ - size and number of active reaction centres of photosynthetic apparatus; $F_{0} / F_{v}-$ efficiency of water-splitting complex; $F_{m} / F_{0}-$ electron transport rate through PSII. 


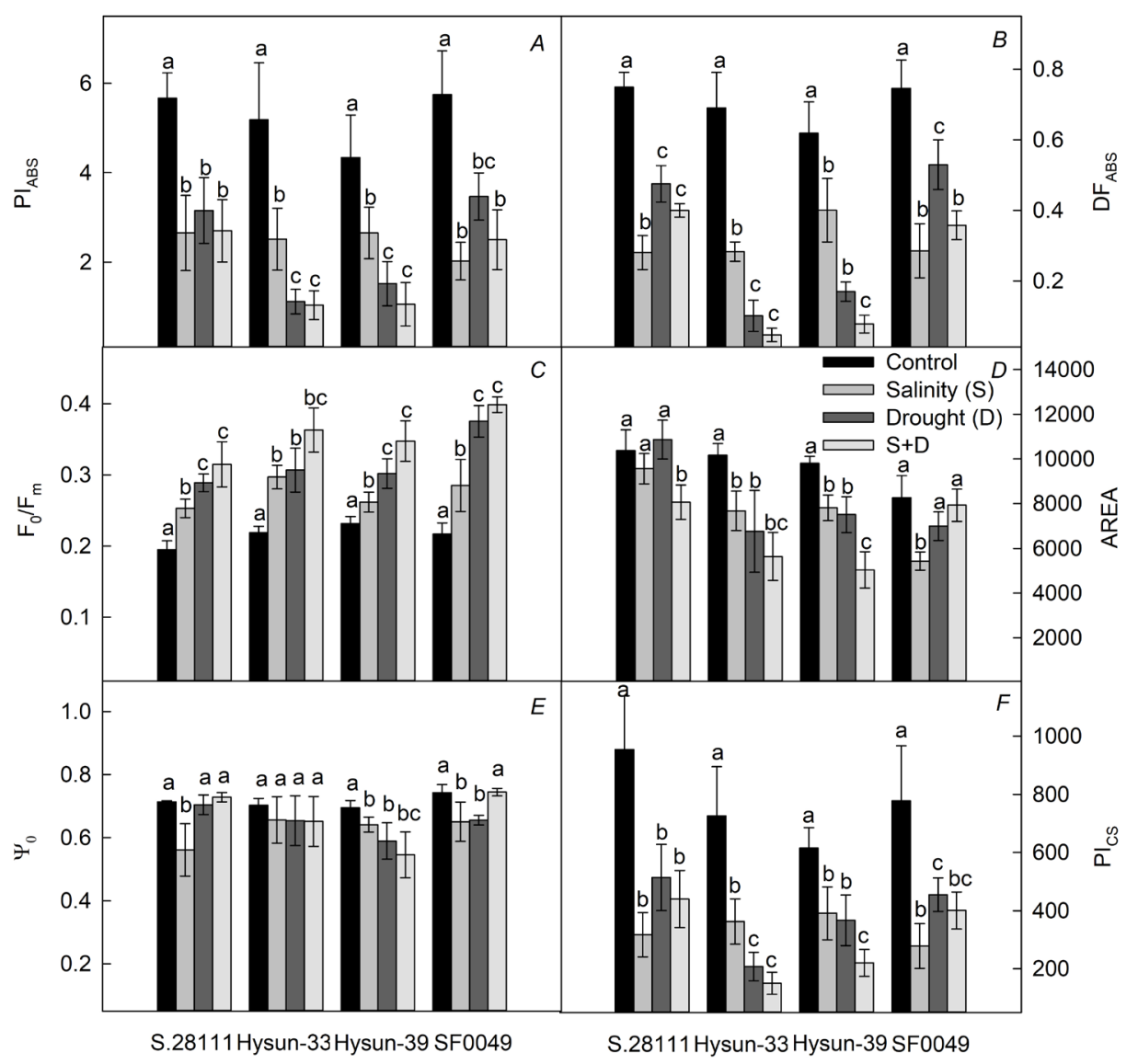

Fig. 2. Effects of salt, drought, and combined $(\mathrm{S}+\mathrm{D})$ stress on quantum efficiencies, flux ratios or yields: $\mathrm{PI}_{\mathrm{ABS}}(A), \mathrm{DF}_{\mathrm{ABS}}(B), \mathrm{F}_{0} / \mathrm{F}_{\mathrm{m}}$ $(C)$, Area $(D), \psi_{0}(E)$, and $\mathrm{PI}_{\mathrm{CS}}(F)$ of S.28111, Hysun-33, Hysun-39, and SF0049. Vertical line on each bar represents mean standard error $( \pm)$. Values among each genotype with the same letter $(s)$ are not significantly different at $P<0.05$. $\mathrm{PI}_{\mathrm{ABS}}-$ performance index on absorption basis; $\mathrm{DF}_{\mathrm{ABS}}$ - driving force on absorption basis; $\mathrm{F}_{0} / \mathrm{F}_{\mathrm{m}}$ - physiological state of the photosynthetic apparatus; Area - area over the fluorescence curve between $\mathrm{F}_{0}$ and $\mathrm{F}_{\mathrm{m}} ; \psi_{0}$ - yield of electron transport per trapped excitation or probability with which a PSII trapped electron is transferred from reduced $\mathrm{Q}_{\mathrm{A}}$ to $\mathrm{Q}_{\mathrm{B}} ; \mathrm{PI}_{\mathrm{CS}}$ - performance index on cross-section basis.

stress environments was found in Hysun-33 and Hysun-39 as compared to the cultivars S.28111 and SF0049.

Our results showed that NPQ increased under salt, drought, and combined stresses compared with control (Fig. 3). Hysun-33 and Hysun-39 showed greater NPQ under combined stress compared to S.28111 and SF0049. Yield of PSII $\left(\Phi_{\text {PSII }}\right)$, the proportion of open PSII reaction centers ( $\mathrm{q}_{\mathrm{P}}$, photochemical quenching), and relative electron transport (ETR), decreased significantly under salt, drought, and combined stress treatments (Fig. 3). The lowest ETR was found in Hysun-39 under combined stress treatment indicating lesser conversion of absorbed light energy into efficient photochemistry and thus increased dissipation energy. S.28111 showed the lowest decline in ETR, which indicated better photochemistry with less dissipation under combined stress. The coefficient of nonphotochemical quenching $\left(\mathrm{q}_{\mathrm{N}}\right)$ is similar to NPQ. In our study, $\mathrm{q}_{\mathrm{N}}$ was found to be a very sensitive indicator of salt and drought stress in sunflower cultivars.

The pipeline model (Fig. 4) showed alterations in inactive reaction centres in all sunflower cultivars under stressful conditions. The pictorial model shown in Fig. 4 demonstrated the dissipation energy flux per reaction centre $\left(\mathrm{DI}_{0} / \mathrm{RC}\right)$ and absorption flux per reaction centre $(\mathrm{ABS} / \mathrm{RC})$ which were higher under the combined stress compared to control. Trapping per active reaction centre $\left(\mathrm{TR}_{0} / \mathrm{RC}\right)$ increased in Hysun-33 and Hysun-39, whereas in S.28111 and SF0049, it showed a significant increase only under salt stress. Changes in $\mathrm{ET}_{0} / \mathrm{RC}$ were insignificant under the combined stress (Fig. 4). It was observed that energy absorption, transfer, and loss were more affected under the combined stress as compared to single stress. The values obtained from several parameters under the stressful environments were lower than those determined in control plants. Electron transport per absorption flux $\left(\mathrm{ET}_{0} / \mathrm{ABS}\right)$ decreased significantly under salt, drought, and combined stress. Hysun-39 had the highest decline in $\mathrm{ET}_{0} / \mathrm{ABS}$ under combined stress indicating a considerable number of inactive reaction centres. Further, the combined salt and drought stress-treated plants exhibited much higher dissipated energy flux ( $\left.\mathrm{DI}_{0} / \mathrm{ABS}\right)$ than control plants.

The JIP test of each sunflower cultivar was obtained under the salt, drought, and combined stress. Initial step of the JIP test did not show significant differences under salt 


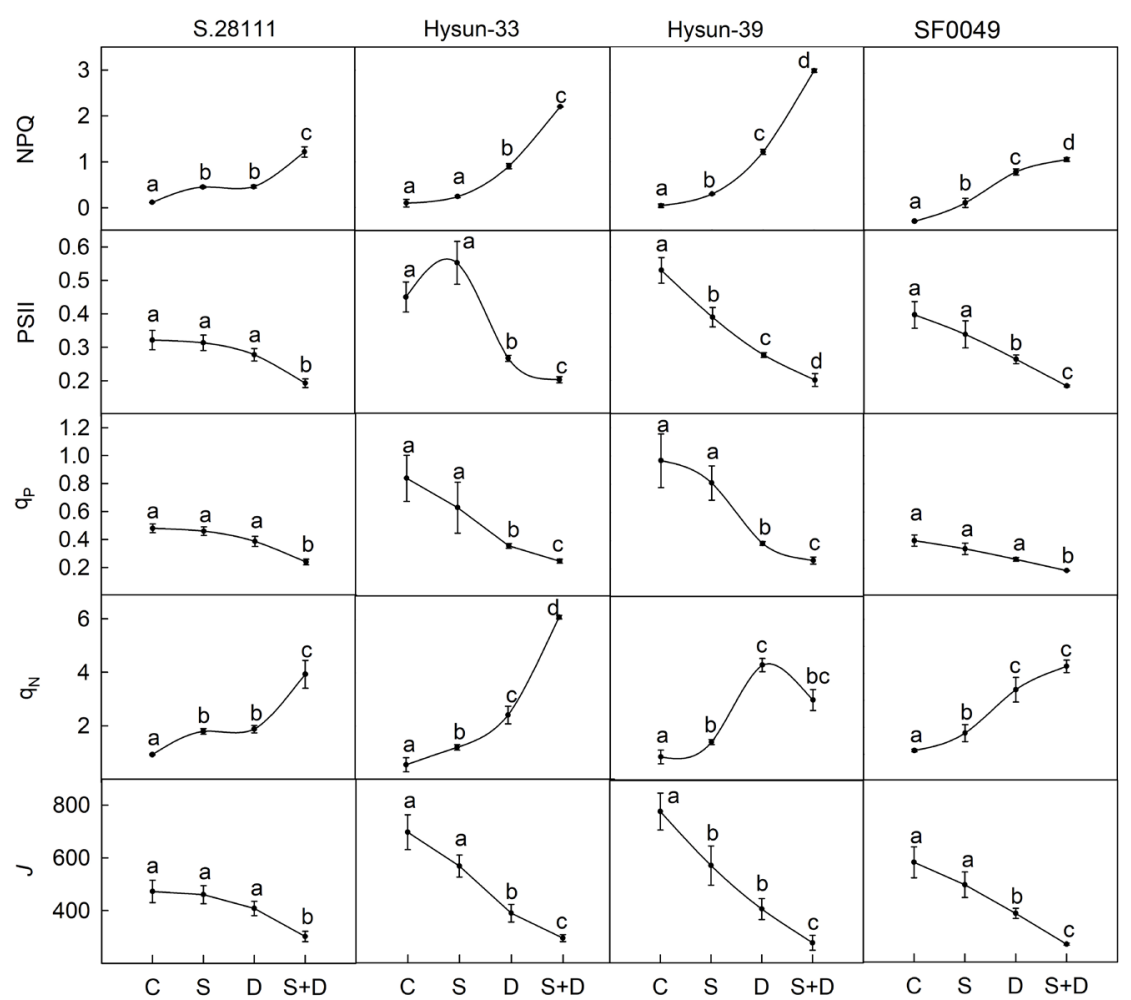

Fig. 3. Effects of salt, drought, and combined $(\mathrm{S}+\mathrm{D})$ stress on quenching parameters: nonphotochemical quenching (NPQ), effective quantum yield of PSII photochemistry $\left(\Phi_{\mathrm{PSII}}\right)$, photochemical quenching $\left(\mathrm{q}_{\mathrm{p}}\right)$, nonphotochemical quenching coefficient $\left(\mathrm{q}_{\mathrm{N}}\right)$, and linear electron transport rate $(J)$ of S.28111, Hysun-33, Hysun-39, and SF0049. Vertical lines represent mean standard error $( \pm)$. Values among each genotype with the same letter(s) are not significantly different at $P<0.05$.
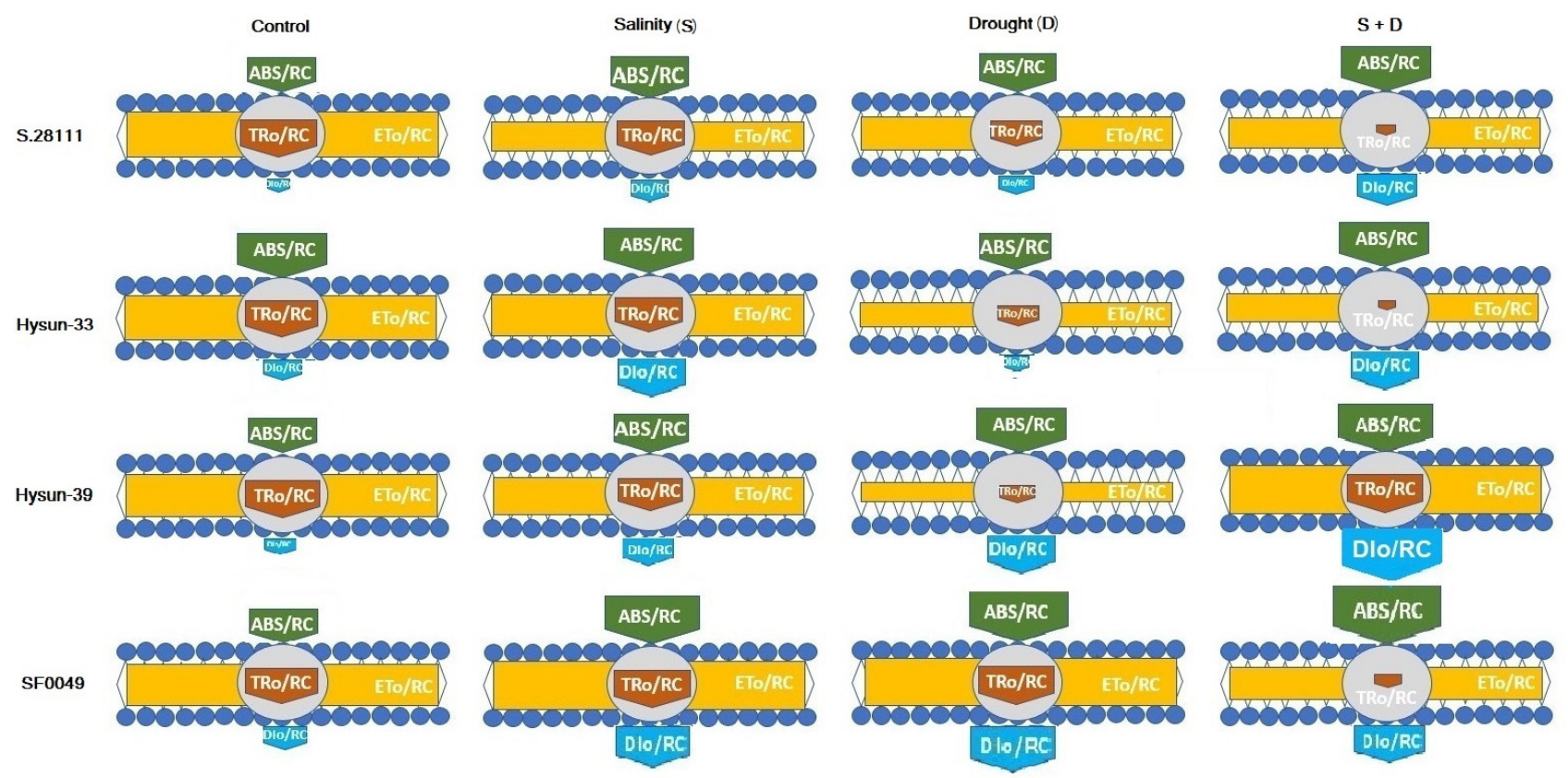

Fig. 4. Effects of salt, drought, and combined (S+D) stress on specific energy fluxes of S.28111, Hysun-33, Hysun-39, and SF0049. The diagram shows the variation of absorption flux per reaction center (ABS/RC), trapped energy flux per reaction center $\left(\mathrm{TR}_{0} / \mathrm{RC}\right)$, electron transport flux per reaction center $\left(\mathrm{ET}_{0} / \mathrm{RC}\right)$, and energy dissipation flux per reaction center $\left(\mathrm{DI}_{0} / \mathrm{RC}\right)$ for four treatments, namely, control, salt, drought, and salt plus drought. This model was developed by the values of four fluxes. These values were normalized so that values of each of the four fluxes can be compared within variety as well as within treatment. The model displays fluxes in various shapes; the size of each shape is proportional to corresponding normalized value.

and drought stresses. In combined stress, all tested cultivars exhibited a slower rise and reached a much lower peak of fluorescence (Fig. 6). S.28111 and SF0049 showed a lower decline in the fluorescence intensity of the OJIP transient as compared to Hysun-33 and Hysun 39 (Fig. 6A-D). 


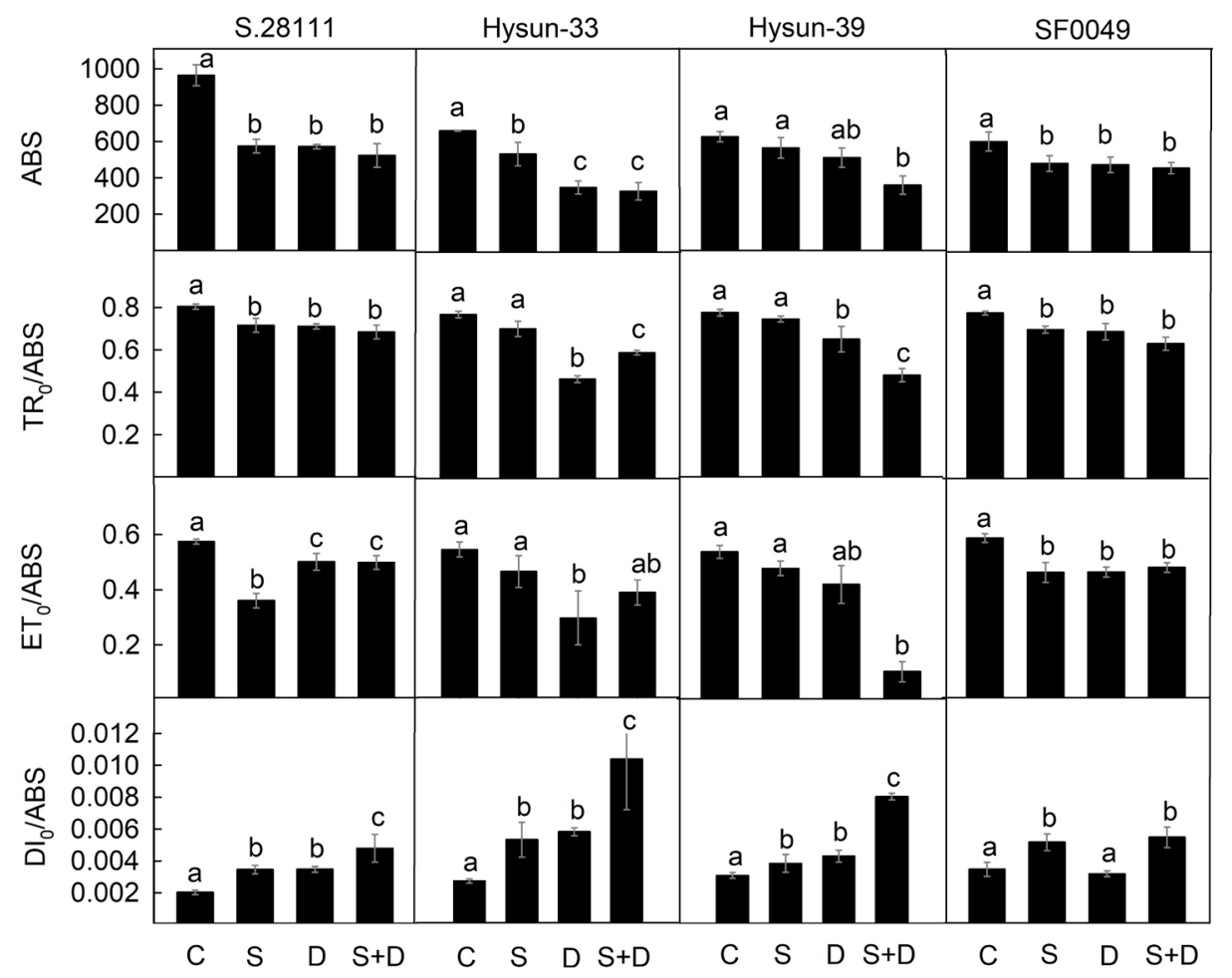

Fig. 5. Effects of salt (S), drought (D), and combined (S+D) stress on phenomenological energy fluxes within a leaf and calculated per equal absorption (ABS, $\mathrm{TR}_{0} / \mathrm{ABS}$ - trapping per absorption, $\mathrm{ET}_{0} /$ ABS - electron transport flux per absorption, and $\mathrm{DI}_{0} / \mathrm{ABS}$ energy dissipation per absorption) of S.28111, Hysun-33, Hysun-39, and SF0049. Vertical lines represent mean standard error $( \pm)$. Values among each genotype with the same letter(s) are not significantly different at $P<0.05$.

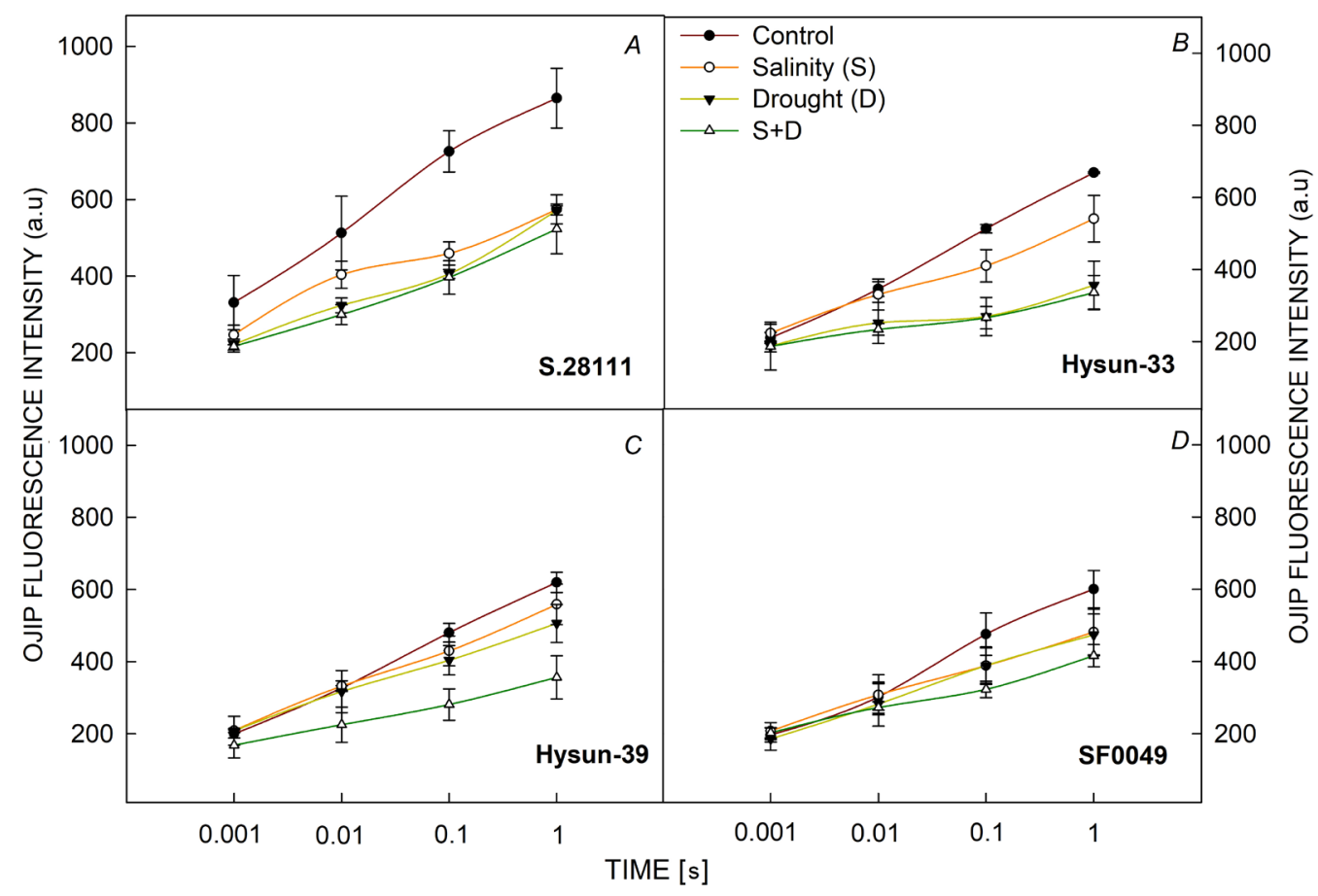

Fig. 6. Effects of salt (S), drought (D), and combined (S+D) stress on chlorophyll a fluorescence induction curve of $\mathrm{S} .28111(A)$, Hysun-33 (B), Hysun-39 $(C)$, and SF0049 (D). Vertical lines represent mean standard error $( \pm)$.

PSI efficiency: Total performance index $\left(\mathrm{PI}_{\mathrm{tot}}\right)$ decreased significantly in Hysun-33 and Hysun-39 under combined salt and drought environment. SF0049 showed the highest $\mathrm{PI}_{\text {tot }}$ under combined salt and drought stresses as compared to other three genotypes (Fig. 7A). An insignificant difference was found between S.28111, Hysun-33, and Hysun-39 under salt stress with their respective controls. However, the highest $\mathrm{PI}_{\text {tot }}$ was observed in S.28111 under drought stress. The parameter $\delta_{\mathrm{R} 0}$, expressing the probability that an electron is transported from reduced 


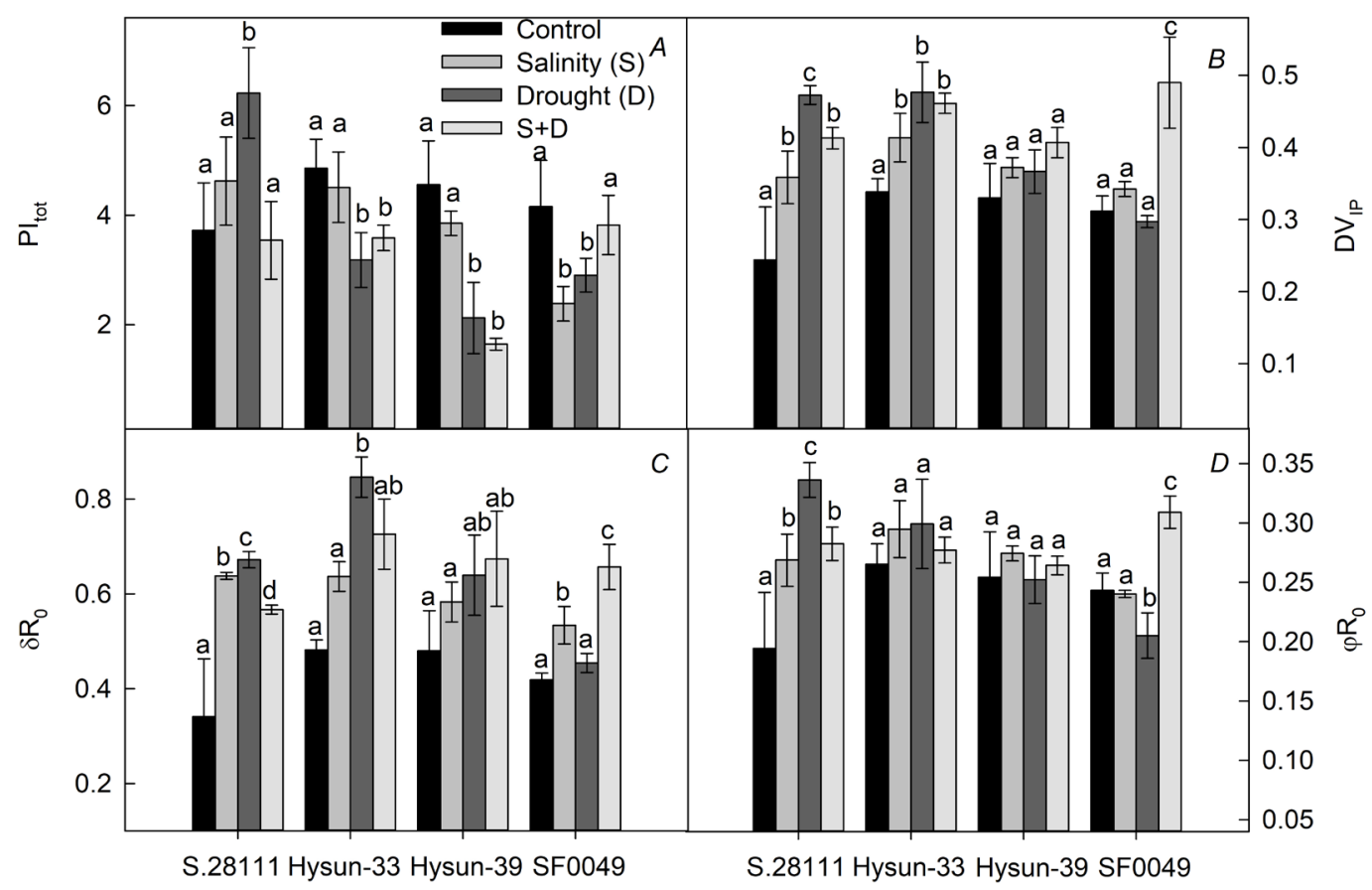

Fig. 7. Effects of salt (S), drought (D), and combined (S+D) stress on PSI activities, i.e., $\mathrm{PI}_{\mathrm{tot}}(A), \Delta \mathrm{V}_{\mathrm{IP}}(B), \delta_{\mathrm{R} 0}(C)$, and $\varphi_{\mathrm{R} 0}(D)$ of S.28111, Hysun-33, Hysun-39, and SF0049. Vertical line on each bar represents mean standard error ( \pm ). Values among each genotype with the same letter $(s)$ are not significantly different at $P<0.05$. $\mathrm{PI}_{\mathrm{tot}}$ - total performance index; $\Delta \mathrm{V}_{\mathrm{IP}}-$ amplitude of the relative variable fluorescence of the I-to-P-rise; $\delta_{\mathrm{R} 0}$ - probability that an electron is transported from reduced PQ to electron acceptor side of PSI; $\varphi_{\mathrm{R} 0}-$ quantum yield for reduction of the end electron acceptors at the PSI acceptor side.

PQ to electron acceptor side of PSI, increased under single salt and drought stress environments (Fig. 7C). SF0049 showed the lowest increase of $\delta_{\mathrm{R} 0}$ under salt and drought environments, whereas the highest increase was observed under combined stress. However, Hysun-33 showed a substantial increase in $\delta_{\mathrm{R} 0}$ under stressful environments, particularly in drought stress. The amplitude of the relative variable fluorescence of the I-to-P rise $\left(\Delta V_{\text {IP }}\right)$ increased in all genotypes under stressful environments. The highest $\Delta V_{\text {IP }}$ was found in SF0049 under combined stress compared to Hysun-33, Hysun-39, and SF0049 (Fig. $7 B$ ). The lowest increase in terms of percentage was observed in Hysun-39 under combined stress. Quantum yield for reduction of the end electron acceptors at the PSI acceptor side $\left(\varphi_{\mathrm{R} 0}\right)$ increased insignificantly in Hysun-33, Hysun-39, and SF0049 under single salt and drought stress; whereas the significant increase was observed in S.28111 under salt and drought stress (Fig. 7D). Hysun-33 and Hysun-39 showed insignificant difference in $\varphi_{\mathrm{R} 0}$ under combined stress compared to their respective controls.

Decline in $\mathrm{ABS} / \mathrm{CS}, \mathrm{TR}_{0} / \mathrm{CS}, \mathrm{RC} / \mathrm{CS}, \mathrm{RC} / \mathrm{ABS}$, and $\varphi_{\mathrm{P} 0} /\left(1-\varphi_{\mathrm{P} 0}\right)$ (efficiency of light reaction) were found under drought and salt stress compared to control (Table 1S, supplement). Hence, S.28111 had better tolerance in terms of photochemistry of PSII under salt, drought, and combined stress compared to Hysun-33, Hysun-39, and SF0049.

$\mathrm{Na}^{+}, \mathrm{K}^{+}$and $\mathrm{Cl}^{-}$ions: Studies have shown that salt stress affects the photosynthesis, plant development, and growth due to ion toxicity, water limitation, and osmotic stress (Mehta et al. 2010, Dąbrowski et al. 2016). A substantial increase in $\mathrm{Na}^{+}$concentration and $\mathrm{Na}^{+} / \mathrm{K}^{+}$ratio was observed in sunflower plants when plants were exposed to salinity alone or in combination of both salt and drought stress as compared to control (Table 1). Under salt stress and combined stress, the $\mathrm{Na}^{+}$concentration increased by 444 and $162 \%$ in S.28111, respectively, 400 and $377 \%$ in Hysun-33, respectively, 569 and $231 \%$ in Hysun-39, respectively, and 200 and $87 \%$ in SF0049, respectively, as compared with control. Hysun-33 and Hysun-39 had greater leaf $\mathrm{Na}^{+}$concentration than that of $\mathrm{S} .28111$ and SF0049 cultivars under salt stress. A small difference was observed under drought compared with control plants. Salt, drought, and combined stress induced a significant increase in $\mathrm{K}^{+}$concentration in sunflower cultivars (Table 1). The increase in $\mathrm{K}^{+}$concentration was insignificant in S.28111, Hysun-33, and Hysun-39, but significantly higher in SF0049. The increase in $\mathrm{K}^{+}$concentration may be attributed to the maintenance of membrane integrity in tested plants which prevents the leakage of $\mathrm{K}^{+}$through membrane. On overall basis, the $\mathrm{Na}^{+} / \mathrm{K}^{+}$ratio increased significantly under salt and combined salt and drought stress compared with control (Table 1). The $\mathrm{Na}^{+} / \mathrm{K}^{+}$ratios were higher in Hysun-33 and Hysun-39 under combined stress. S.28111 and Hysun-33 showed the highest $\mathrm{Na}^{+} /$ $\mathrm{K}^{+}$ratios under salt stress alone (Table 1). However, $\mathrm{Cl}^{-}$ concentration in leaves of each sunflower varieties, i.e., S.28111, Hysun-33, Hysun-39, and SF0049, increased under salt and combined stress (Table 1). An insignificant 
Table 1. Effect of salt, drought, and combined stress on $\mathrm{Na}^{+}, \mathrm{K}^{+}, \mathrm{Cl}^{-}$, and MDA contents of four sunflower (Helianthus annuus L.) cultivars.

\begin{tabular}{|c|c|c|c|c|c|c|}
\hline & Treatments & S.28111 & Hysun-33 & Hysun-39 & SF0049 & Mean \\
\hline \multirow{5}{*}{$\begin{array}{l}\text { Leaf } \mathrm{Na}^{+} \\
{\left[\mathrm{mg} \mathrm{g}^{-1}(\mathrm{DM})\right]}\end{array}$} & Control & $5.33 \pm 0.33$ & $4.33 \pm 0.88$ & $5.33 \pm 0.33$ & $5.00 \pm 1.00$ & 4.99 \\
\hline & Salinity & $29.00 \pm 0.58$ & $21.67 \pm 1.45$ & $35.67 \pm 0.88$ & $15.00 \pm 0.58$ & 25.33 \\
\hline & Drought & $7.00 \pm 0.57$ & $8.00 \pm 0.57$ & $7.67 \pm 1.33$ & $9.67 \pm 1.45$ & 8.08 \\
\hline & $\mathrm{S}+\mathrm{D}$ & $14.00 \pm 1.52$ & $20.67 \pm 0.33$ & $17.67 \pm 0.88$ & $9.33 \pm 0.67$ & 15.42 \\
\hline & Varietal mean & 13.83 & 13.67 & 16.58 & 9.75 & 13.46 \\
\hline \multirow{5}{*}{$\begin{array}{l}\text { Leaf } \mathrm{K}^{+} \\
{\left[\mathrm{mg} \mathrm{g}^{-1}(\mathrm{DM})\right]}\end{array}$} & Control & $25.00 \pm 1.00$ & $24.67 \pm 0.88$ & $24.67 \pm 0.33$ & $26.00 \pm 0.00$ & 25.08 \\
\hline & Salinity & $35.33 \pm 0.33$ & $34.00 \pm 1.53$ & $32.67 \pm 0.88$ & $44.33 \pm 1.20$ & 36.58 \\
\hline & Drought & $35.00 \pm 1.15$ & $32.33 \pm 1.33$ & $36.00 \pm 2.08$ & $39.67 \pm 1.45$ & 35.75 \\
\hline & $\mathrm{S}+\mathrm{D}$ & $35.33 \pm 0.88$ & $34.33 \pm 1.20$ & $32.00 \pm 0.58$ & $36.67 \pm 0.33$ & 34.58 \\
\hline & Varietal mean & 32.67 & 31.33 & 31.33 & 36.67 & 33.00 \\
\hline \multirow[t]{5}{*}{$\mathrm{Na}^{+} / \mathrm{K}^{+}$ratio } & Control & $0.21 \pm 0.005$ & $0.17 \pm 0.03$ & $0.22 \pm 0.012$ & $0.19 \pm 0.04$ & 0.20 \\
\hline & Salinity & $0.82 \pm 0.01$ & $0.64 \pm 0.07$ & $1.09 \pm 0.002$ & $0.34 \pm 0.02$ & 0.72 \\
\hline & Drought & $0.20 \pm 0.01$ & $0.25 \pm 0.02$ & $0.22 \pm 0.046$ & $0.25 \pm 0.04$ & 0.22 \\
\hline & $\mathrm{S}+\mathrm{D}$ & $0.40 \pm 0.05$ & $0.60 \pm 0.03$ & $0.55 \pm 0.023$ & $0.25 \pm 0.02$ & 0.45 \\
\hline & Varietal mean & 0.41 & 0.42 & 0.52 & 0.26 & 0.40 \\
\hline \multirow{5}{*}{$\begin{array}{l}\text { Leaf } \mathrm{Cl}^{-} \\
{\left[\mathrm{mg} \mathrm{g}^{-1}(\mathrm{DM})\right]}\end{array}$} & Control & $15.00 \pm 1.84$ & $14.00 \pm 0.81$ & $13.00 \pm 2.04$ & $18.00 \pm 1.02$ & 15.00 \\
\hline & Salinity & $28.00 \pm 1.79$ & $31.00 \pm 3.36$ & $36.00 \pm 3.29$ & $25.00 \pm 2.27$ & 30.00 \\
\hline & Drought & $14.00 \pm 1.95$ & $15.00 \pm 0.51$ & $11.00 \pm 1.45$ & $16.00 \pm 2.82$ & 14.00 \\
\hline & $\mathrm{S}+\mathrm{D}$ & $25.00 \pm 1.61$ & $29.00 \pm 1.21$ & $32.00 \pm 1.94$ & $24.00 \pm 2.87$ & 27.50 \\
\hline & Varietal mean & 20.50 & 22.25 & 23.00 & 20.75 & 21.62 \\
\hline \multirow{5}{*}{$\begin{array}{l}\text { Electrolyte } \\
\text { leakage [\%] }\end{array}$} & Control & $25.00 \pm 0.64$ & $31.00 \pm 0.95$ & $24.00 \pm 7.84$ & $29.00 \pm 3.92$ & 27.25 \\
\hline & Salinity & $36.00 \pm 3.42$ & $42.00 \pm 1.29$ & $45.00 \pm 0.93$ & $39.00 \pm 2.73$ & 40.5 \\
\hline & Drought & $40.00 \pm 8.65$ & $41.00 \pm 3.86$ & $43.00 \pm 16.89$ & $42.00 \pm 1.90$ & 41.5 \\
\hline & $\mathrm{S}+\mathrm{D}$ & $58.00 \pm 6.89$ & $62.00 \pm 4.05$ & $65.00 \pm 12.25$ & $53.00 \pm 0.55$ & 59.5 \\
\hline & Varietal mean & 39.75 & 44.00 & 44.25 & 40.75 & 42.19 \\
\hline \multirow{5}{*}{$\begin{array}{l}\text { MDA content } \\
{\left[\mathrm{mg} \mathrm{g}^{-1}(\mathrm{FM})\right]}\end{array}$} & Control & $1.70 \pm 0.17$ & $1.80 \pm 0.22$ & $1.60 \pm 0.27$ & $1.90 \pm 0.07$ & 1.75 \\
\hline & Salinity & $2.20 \pm 0.23$ & $3.10 \pm 0.49$ & $3.60 \pm 0.68$ & $2.60 \pm 0.07$ & 2.88 \\
\hline & Drought & $2.80 \pm 0.31$ & $3.40 \pm 0.46$ & $3.50 \pm 0.69$ & $3.10 \pm 0.07$ & 3.20 \\
\hline & $\mathrm{S}+\mathrm{D}$ & $3.50 \pm 0.36$ & $4.50 \pm 0.60$ & $4.80 \pm 0.68$ & $4.01 \pm 0.70$ & 4.20 \\
\hline & Varietal mean & 2.55 & 3.20 & 3.38 & 2.90 & 3.01 \\
\hline
\end{tabular}

difference between treated and control plants was found under drought stress showing minimum $\mathrm{Cl}^{-}$concentration in SF0049, while maximum in Hysun-39. Under salt stress, a significant variation among the cultivars was observed in $\mathrm{Cl}^{-}$concentration.

An increase in MDA contents was observed in tested plants under stress conditions as compared with control (Table 1). In this investigation, MDA contents increased significantly under salt, drought, and combined stresses. MDA is the end product of lipid peroxidation in the cellular membrane. Combined salt and drought stress had more pronounced on S.28111, Hysun-33, Hysun-39, and SF0049. Among the cultivars, MDA content was higher in Hysun-39, whereas a lesser concentration was observed in S.28111. A minor variation was found between salt and drought stress alone in all sunflower cultivars. Lower MDA contents in S.28111 compared to Hysun-33, Hysun-39, and SF0049 corresponded to the lower lipid peroxidation indicating better protection against oxidative damage due to salt and drought stress. Single and combined stress significantly increased the electrolyte leakage (EL) in all sunflower cultivars. In terms of varietal mean, the highest EL (44.3\%) was observed in Hysun-39 under combined stress treatment, whereas the lowest EL (39.8\%) was observed in S.28111 (Table 1).

\section{Discussion}

In the present investigation, Chl $a$ fluorescence transients through JIP-test were analyzed in S.28111, Hysun-33, Hysun-39, and SF0049 in order to examine the response of photosynthetic apparatus to combined stress. Sunflower plants were grown under salt, drought, and combined stress along with their control. Ion accumulation and detailed photochemistry of PSII of sunflower cultivars under stressed conditions were investigated.

$\mathrm{F}_{\mathrm{v}} / \mathrm{F}_{\mathrm{m}}$ is not sensitive to early and moderate stresses but decreased under salt and drought stress. A small decline in 
$\mathrm{F}_{\mathrm{v}} / \mathrm{F}_{\mathrm{m}}$ might be due to an increase in photorespiration of $\mathrm{C}_{3}$ plants under osmotic stress (Maxwell and Johnson 2000, Zivcak et al. 2013). The decline in $\mathrm{F}_{\mathrm{v}} / \mathrm{F}_{\mathrm{m}}$ ratio was related to decrease in $\mathrm{F}_{\mathrm{m}}$ values under salt, drought, and combined stress indicating the disruption of antenna complex of PSII and increased dissipated energy, destruction of reaction center at PSII, and impaired ribulose-1,5-bisphosphate (RuBP) regeneration ability (Vieira Santos et al. 2001), thus, electron transport capacity of PSII was reduced. The $F_{v} / F_{m}$ ratio in Hysun-39 decreased up to $38 \%$ (more than additive effects) under combined salt and drought stress. It is suggested that sunflower cultivar S.28111 maintained lesser disruption in antenna complex and RuBP regeneration ability under combined stress. Reduction in the rate of electron transport from $\mathrm{Q}_{\mathrm{A}}$ to $\mathrm{Q}_{\mathrm{B}}$ leads to strong photodamage, loss in reaction center, and decline in size and number of active reaction centers of photosynthetic apparatus $\left(\mathrm{F}_{\mathrm{v}} / \mathrm{F}_{0}\right)$. Zaghdoudi et al. (2011) reported that decline in the $\mathrm{F}_{\mathrm{v}} / \mathrm{F}_{0}$ was followed by greater inhibition of PSI and PSII due to interruption of electron flow at their oxidation sides. Further, $\mathrm{F}_{0} / \mathrm{F}_{\mathrm{v}}$ determines the efficiency of water-splitting complex (Sun et al. 2016). Results showed that the efficiency of water-splitting complex increased under combined salt and drought stress. Hysun-33 and SF0049 reached the highest $\mathrm{F}_{0} / \mathrm{F}_{\mathrm{v}}$ under drought and combined stress. S.28111 showed a lesser increase in all stress treatments. Possibly, the PSII has more inactive reaction centers under stress conditions and therefore it was unable to accept more electrons from water-splitting complex due to the blockage at PSII acceptor side. The lower electron transport through PSII lowered down the pressure and improved the efficiency of water-splitting complex in sunflower cultivars, especially, in SF0049 and Hysun-33, under stress environment.

The quantum yield baseline $\left(\mathrm{F}_{0} / \mathrm{F}_{\mathrm{m}}\right)$ can be used as a stress indicator and its normal range varies between 0.15 and 0.25 in sunflower plants. $F_{0} / F_{m}$ increased under salt stress indicating that the rate of plastoquinone reduction $\left(Q_{A}\right)$ was much higher than the rate of oxidation $\left(Q_{B}\right)$. Performance index $\left(\mathrm{PI}_{\mathrm{ABS}}\right)$ is primarily a stress indicator and it decreased in all sunflower cultivars under salt, drought, and combined stresses (Mehta et al. 2010, Kalaji et al. 2018). Hysun-33 and Hysun-39 showed additive effects, whereas S.28111 and SF0049 showed less additive effects under combined stress. The substantial reduction in the ratio of trapping and dissipation fluxes had greater effects on $\mathrm{PI}_{\mathrm{ABS}}$. It was observed that the $\Psi_{0}$ values were affected after single stresses compared with control, whereas they were not significantly affected by combined stress treatment except in Hysun-39 (Fig. 2E,F). Decline in $\Psi_{0}$ can be interpreted as the blockage of electron flow from reduced $\mathrm{Q}_{\mathrm{A}}$ to $\mathrm{Q}_{\mathrm{B}}$ due to salt, drought, and combined stresses. Decreased in light and biochemical reactions confirmed the greater decline in net photosynthetic rate in Hysun-39 and Hysun-33. Greater decline in $\Psi_{0}$ values in Hysun-39 suggested that PSII electron transfer from reduced $\mathrm{Q}_{\mathrm{A}}$ to $\mathrm{Q}_{\mathrm{B}}$ was affected. The indicator of driving force in PSII based on absorption basis, $\mathrm{DF}_{\mathrm{ABS}}$, greatly decreased under stress. However, $\mathrm{DF}_{\mathrm{ABS}}$ showed that Hysun-33 and Hysun-39 had the lowest number of active
RCs and highest inhibition of the reoxidation of reduced $\mathrm{Q}_{\mathrm{A}}$ under combined stress. Furthermore, S.28111 and SF0049 showed better primary photochemical reaction as compared to Hysun-33 and Hysun-39 under stressed conditions.

Our results showed that NPQ, PSII, $\mathrm{q}_{\mathrm{P}}, \mathrm{q}_{\mathrm{N}}$, and $J$ were less affected in sunflower under salt stress compared to drought and combined stresses (Fig. 3). However, Hysun-39 and Hysun-33 were found to be more sensitive to the combined stress. The downregulation of PSII photochemical efficiency caused by stresses reflected the significant decrease in maximum quantum yield of PSII under stresses. Linear electron transport rate (rETR) is sensitive to water stresses which increased gradually with moderate to severe stress. The lowest rETR was found in Hysun-39 under combined stress treatment indicating Hysun-39 was unable to convert the absorbed light energy into efficient photochemistry and increase dissipation energy. S.28111 had the lowest decline in relative electron transport which indicated better photochemistry with lesser dissipation under the combined stress. The $\mathrm{q}_{\mathrm{p}}$ represents the proportion of excited electrons and their conversion to the chemical energy in PSII reaction centers. Krause and Weis (1991) described that the $\mathrm{q}_{\mathrm{P}}$ value depends on the presence of primary electron acceptor of PSII, i.e., $\mathrm{Q}_{\mathrm{A}}$ in an oxidized state. S.28111 showed greater efficiency and had better PSII functional state compared to Hysun cultivars under combined salt and drought stress. The greater decrease in $\mathrm{q}_{\mathrm{P}}$ might be due to the damaging effects of salt, drought, and combined stress on the efficiency of complete photochemical process or the separation of LHCII from PSII reaction center ( $\mathrm{Wu}$ et al. 2010). Likewise, Netondo et al. (2004) described that higher NPQ values protect the photosynthetic machinery against photodamage under osmotic stress conditions. Higher photoprotective capacity strives with photochemistry for absorbed light energy and caused downregulation of photosynthetic capacity, which was observed by the decline in quantum yield of PSII $\left(\Phi_{\text {PSII }}\right)$. S.28111 and SF0049 did not show greater downregulation in photosynthetic capacity under single and combined stress environments. In this research, $\mathrm{q}_{\mathrm{N}}$ was found to be a more sensitive indicator of salt and drought stress in sunflower cultivars as compared to combined stress. It was evident from the data that the $\mathrm{q}_{\mathrm{N}}$ affected the $F_{v}$ rather than $F_{0}$. It is therefore suggested that the main target of salt and drought stress is the second electron acceptor $\left(\mathrm{Q}_{\mathrm{B}}{ }^{-}\right)$on acceptor side of PSII and blocking the electron transport beyond $\mathrm{Q}_{\mathrm{A}}^{-}$.

To compare and explain the mechanism of tolerance in sunflower cultivars, a model is presented in Fig.4. It refers to the reaction center in the membrane and deals with the specific energy fluxes (ABS, $\mathrm{ET}_{0}, \mathrm{TR}_{0}$, and $\mathrm{DI}_{0}$ ) per $\mathrm{RC}$. Whereas Fig. 5 and 6 refer to the phenomenological energy fluxes such as $\mathrm{TR}_{0}, \mathrm{ET}_{0}$, and $\mathrm{DI}_{0}$ per ABS. Fig. 4 suggested that fractions of $\mathrm{RC}\left(\mathrm{ABS} / \mathrm{RC}\right.$ and $\left.\mathrm{DI}_{0} / \mathrm{RC}\right)$ became dissipative centers to prevent the photooxidative damage of photosynthetic apparatus. Under combined stress, a significant increase was observed in the energy fluxes for absorption of photon per active reaction center (ABS/RC) and energy dissipation flux per reaction center $\left(\mathrm{DI}_{0} / \mathrm{RC}\right)$ 
in Hysun-33 and Hysun-39 as compared to S.28111 and SF0049. Thus, the higher values of ABS/RC indicated the reduced number of active reaction centers under combined stress. This might be due to high proton gradient through the thylakoid membrane under stress, which results in active reaction center becoming a dissipative center and convert violaxanthin into zeaxanthin to prevent the oxidative damage under extreme conditions. It is clear from the Fig. 5 and Table 1S that salt, drought, and combined stress led to a significant decrease in electron transport per ABS and per CS. A clear difference was observed in trapping efficiency per $\mathrm{CS}_{\mathrm{m}}$ compared with control in each cultivar. The dissipation per ABS and CS was the most affected and more than additive in Hysun-33 and Hysun-39 under combined stress (Fig. 5, Table 1S). These results indicated that the combined stress inhibited the electron transport beyond $\mathrm{Q}_{\mathrm{A}}^{-}\left(\mathrm{ET}_{0} / \mathrm{CS}_{\mathrm{m}}\right.$ and $\left.\mathrm{ET}_{0} / \mathrm{ABS}\right)$ in sunflower cultivars, specially, in Hysun-33 and Hysun-39. There is an insignificant change in the antenna size, chlorophyll density (ABS/RC, TR $0 / \mathrm{RC}$ ) and heat dissipation $\left(\mathrm{DI}_{0} / \mathrm{RC}\right.$, $\mathrm{DI}_{0} / \mathrm{CS}, \mathrm{DI}_{0} / \mathrm{ABS}$ ) in SF0049 and S.28111. It is suggested that combined stress inhibited the electron flow from $\mathrm{Q}_{\mathrm{A}}$ to $\mathrm{Q}_{\text {в }}$ on the PSII acceptor side, especially in Hysun-39, but did not produce any substantial effect on the PSII donor side in S.28111, Hysun-39, and SF0049. Further, the PSII light-harvesting function was less affected under combined stress in S.28111 and SF0049. Based on our results, it was proposed that the greater number of inactive reaction centers was the basic reason for the higher dissipation of absorbed light. The inactivation of reaction centers due to stresses was evidenced by the decline in $\mathrm{RC} / \mathrm{CS}_{0}$ and $\mathrm{TR}_{0} / \mathrm{ABS}$ (Fig. 5, Table $1 \mathrm{~S}$ ). $\mathrm{RC} / \mathrm{CS}_{0}$ expresses the active $\mathrm{RCs}$ in PSII cross-section and its lesser values under combined stress demonstrate a conversion from active to inactive reaction centers (Mehta et al. 2010). TR $\mathrm{TR}_{0} / \mathrm{ABS}$ expresses the average of the maximum primary photochemistry, quantum yield of active reaction centers, and inactive reaction centers. This parameter decreased greatly in Hysun-33 and Hysun-39 under single and combined stress; it displayed inactivation of RCs. This confirmed that the salt and drought stress can damage the active $\mathrm{RCs}$ and decline $\mathrm{PI}_{\mathrm{ABS}}$ suggesting possible inhibition of PSII activities and the rate of electron transport from $\mathrm{PQ}$ to P700. A greater decline in $\mathrm{ABS} / \mathrm{CS}, \mathrm{TR}_{0} / \mathrm{CS}$, and $\mathrm{RC} / \mathrm{CS}$ was observed in Hysun-33 and Hysun-39 as compared to S.28111 under salt, drought, and combined stress. It was evident from the data that abiotic stress not only inactivated PSII reaction centers and reduced antenna size and function but also curtailed specific rate of electron excitation in open RCs. Results revealed that ET/CS synergistically decreased in Hysun-39 under combined stress as compared with control (Table 1S). It was suggested that greater susceptibility of Hysun-39 to combined stress may be due to the reduced capacity of nonassimilatory electron pathways, i.e., Mehler's reaction (Asada 1999, Takahashi and Murata 2005). It is suggested that quick response of photosynthetic apparatus could be a decisive feature for the tolerance in sunflower cultivars under salt, drought and combined stress.

The lower JIP curve in Hysun-33 and Hysun-39 indicated the accumulation of inactive reaction centers of PSII as compared to S.28111 and SF0049 under combined stress. Insignificant changes at ' $O$ ' step indicated that there was a little or no loss of energy transfer to reaction centers from antenna complex (Baker 2008). This may be due to higher number of inactive reaction centers (lower peak) where electrons cannot be transferred from reduced plastoquinone $\left(\mathrm{Q}_{\mathrm{A}}^{-}\right)$or LHCII to PSII core (Murkowski 2002). Sunflower cultivars showed rise in 'J' step under single salt stress. It is evident from J and I step that the Hysun genotypes showed downregulation in electron transport beyond $\mathrm{Q}_{\mathrm{A}}$ as compared to other cultivars. Fluorescence rises to ' $\mathrm{P}$ ' level because a due to electron accumulation on PSI electron acceptor (Papageorgiou and Govindjee 2004). Last level represents the values for $\mathrm{Q}_{\mathrm{A}}$, $\mathrm{Q}_{\mathrm{B}}{ }^{-}$, and $\mathrm{PQH}_{2}$. Lower J-I-P level in combined stresses as compared to single stress, suggested that stress-induced damages caused reduction in PSI efficiency to accept electrons and reduced PQ pool size in sunflower.

$\mathrm{PI}_{\text {tot }}$ is the performance index for energy conservation from photons absorbed by PSII to the reduction flux (RE) of PSI end electron acceptors. $\mathrm{PI}_{\text {tot }}$ also confirmed the better performance of PSI acceptor side in S.28111 and SF0049 as compared to Hysun-33 and Hysun-39 under combined stress. It is a multiparametric expression which associates a density of reaction centers, quantum yield of primary photochemistry, ability to transfer electrons between PSII and PSI, and the efficiency with which electrons move from the reduced intersystem electron acceptors to the PSI end electron acceptors, i.e., $\delta_{\mathrm{R} 0}$ (Strasser et al. 2010). A significant increase in $\delta_{\mathrm{R} 0}$ was observed under salt, drought, and combined stress in all sunflower genotypes. Decrease in $F_{P}$ indicated a blockage in the electron transport from reaction centers of PSII to $\mathrm{Q}_{\mathrm{A}}$ and increased the dissipation of excited states of Chls (Oukarroum et al. 2015). Abiotic stress affects the IP-phase and salt and drought stress can have genotype-dependent effects on the IP amplitude (Oukarroum et al. 2009). $\Delta \mathrm{V}_{\mathrm{IP}}$ is an important parameter to measure the ratio of PSII:PSI and can be used as an indicator for the changes in the PSI content (Ceppi et al. 2012). $\Delta \mathrm{V}_{\mathrm{IP}}$ indicates that the amplitude of the IPphase expresses the electron transport efficiency around the PSI in reducing ferredoxin and NADP. The IP-phase expresses the relative abundance of PSI as compared to PSII and a greater PSI/PSII ratio allows for a fast reduction of ferredoxin. This phase seems to be depressed from the stresses that suppress the Calvin cycle (Oukarroum 2009). Higher values in SF0049 under combined stress expressed a larger pool of electron acceptor in PSI. Increased values of this parameter might be a reason for enhancement of stress tolerance and reducing the effects of one or both stresses maintaining the higher pool size in PSI. However, the photochemistry of PSII was found to be more sensitive to salt and drought stress compared to PSI. The value of $\phi_{\mathrm{R} 0}$ increased by single stress, while under the combined stress, the value of $\phi_{\mathrm{R} 0}$ reversed in all tested genotypes except SF0049. A higher transport of electrons might be due to a larger pool size of end electron acceptors at the PSI and stress activation of dark reactions. These results indicate a higher tolerance of PSI activity to 
salt and drought stress in general. It is obvious from this investigation that the combined stress mainly inactivated the PSII RCs and blocked the electron flow from $\mathrm{Q}_{\mathrm{A}}$ to $\mathrm{Q}_{\mathrm{B}}$ in the electron transport chain in sunflower cultivars. The greater inactivation was observed in Hysun-33 and Hysun-39 compared to SF0049 and S.28111. A significant increment in $\phi_{\mathrm{R} 0}$ was found in S.28111 and SF0049 under combined stress which means the proper electron transfer towards the end electron acceptors of PSI.

Salt and drought stress caused membrane lipid peroxidation and produced MDA with other compounds (Nxele et al. 2017). The present investigation has shown that salt and drought stress alone or in the combination induced the oxidative stress evidenced by MDA production in sunflower. Hysun-39 had the highest MDA contents compared to other cultivars, whereas S.28111 had the lowest MDA contents under stressful conditions. Salt and drought stress damages the membrane integrity and promoted higher MDA contents which means the leakage of important ions and increasing accumulation of $\mathrm{Na}^{+}$and $\mathrm{Cl}^{-}$under salt stress. All these finding support the data obtained and illustrated in photochemical results. Our results showed the increase of $\mathrm{Na}^{+}$concentration and $\mathrm{Na}^{+} /$ $\mathrm{K}^{+}$ratio in sunflower under salt alone and combined salt and drought stress (Table 1). The greater $\mathrm{K}^{+} / \mathrm{Na}^{+}$ratios or $\mathrm{K}^{+}$and $\mathrm{Na}^{+}$selectivity and distribution of ions in plants are important criteria for salt tolerance assessment (Gu et al. 2016). Interestingly, SF0049 had lower $\mathrm{Na}^{+}$concentration and $\mathrm{Na}^{+} / \mathrm{K}^{+}$ratio compared to S.28111, Hysun-33, and Hysun-39. It is suggested that SF0049 may belong to a group of plants that are reported as $\mathrm{Na}^{+}$excluders and tolerate $\mathrm{NaCl}$ stress (Acosta-Motos et al. 2017). Thus, the leaf $\mathrm{K}^{+} / \mathrm{Na}^{+}$ratio could be used as a salt tolerance indicator in sunflower cultivars. However, the availability of essential nutrients is normally reduced under saline environments (Acosta-Motos et al. 2017). Electrolyte leakage (EL) indicates the instability of membrane. The EL in tested sunflower cultivars increased under single and combined stress environments. S.28111 and SF0049 had the lowest EL under single and combined salt and drought stress. Abnormaly increased reactive oxygen species (ROS) decreased cell membrane stability which leads to the leakage of important ions. Lower $\mathrm{K}^{+}$concentrations in Hysun-33 and Hysun-39 may be due to the greater electrolyte leakage and lesser membrane stability under combined salt and drought treatments.

Responses of photosynthetic apparatus in sunflower cultivars varied according to the type and severity of the stress. Fluorescence parameters indicated that the photosynthetic apparatus of cultivar S.28111 was the most tolerant against the stress as compared to other cultivars. Besides the most frequently used parameters, such as $\mathrm{F}_{\mathrm{v}} /$ $\mathrm{F}_{\mathrm{m}}$ ratio, $\mathrm{PI}_{\mathrm{ABS}}$, $\mathrm{q}_{\mathrm{P}}$ or $\mathrm{NPQ}$, the other parameters, such as quenching coefficient (NPQ, qn, qp), performance indexes $\left(\mathrm{PI}_{\mathrm{ABS}}, \mathrm{PI}_{\mathrm{CS}}\right.$, and $\left.\mathrm{PI}_{\mathrm{tot}}\right)$, electron transport rate, phenomenological fluxes, and specific energy fluxes, are also important for the better understanding of PSII functioning under oxidative stresses. The tolerance of S.28111 and SF0049 were related to their lower $\mathrm{Na}^{+} / \mathrm{K}^{+}$ ratio and better operational photochemistry under single and combined stresses. SF0049 had the greater ability to exclude $\mathrm{Na}^{+}$, whereas S.28111 showed the greater capacity to scavenge ROS (supplementary data) during stresses. Further, the absorbed light energy was transferred more efficiently to the reaction centre, due to better electron transport through PSII with lesser dissipation in S.28111 and SF0049 as compared to Hysun cultivars. It is therefore suggested that S.28111 and SF0049 may be used to develop those traits that could be used in crop improvement programs in future.

\section{References}

Acosta-Motos J.R., Ortuño M.F., Bernal-Vicente A. et al.: Plant responses to salt stress: Adaptive mechanisms. Agronomy 7: 18, 2017.

Asada K.: The water-water cycle in chloroplasts: scavenging of active oxygens and dissipation of excess photons. - Annu. Rev. Plant Phys. 50: 601-639, 1999.

Bąba W., Kalaji H.M., Kompała-Bąba A., Goltsev V.: Acclimatization of photosynthetic apparatus of tor grass (Brachypodium pinnatum) during expansion. - PLoS ONE 11: e0156201, 2016.

Baker N.R.: Chlorophyll fluorescence: a probe of photosynthesis in vivo. - Annu. Rev. Plant Biol. 59: 89-113, 2008.

Carmak I., Horst W.J.: Effects of aluminum on lipid peroxidation, superoxide dismutase, catalase, and peroxidase activities in root tips of soybean (Glycine max). - Physiol. Plantarum 83: 463-468, 1991.

Ceppi M.G., Oukarroum A., Çiçek N. et al:: The IP amplitude of the fluorescence rise OJIP is sensitive to changes in the photosystem I content of leaves: a study on plants exposed to magnesium and sulfate deficiencies, drought stress and salt stress. - Physiol. Plantarum 144: 277-288, 2012.

Dąbrowski P., Baczewska A.H., Pawluśkiewicz B. et al.: Prompt chlorophyll a fluorescence as a rapid tool for diagnostic changes in PSII structure inhibited by salt stress in perennial ryegrass. - J. Photoch. Photobio. B 157: 22-31, 2016.

Dąbrowski P., Kalaji M.H., Baczewska A.H. et al.: Delayed chlorophyll a fluorescence, MR 820, and gas exchange changes in perennial ryegrass under salt stress. - J. Lumin. 183: 322-333, 2017.

Duncan D.B.: Multiple range and multiple F-test. - Biometrics 11: 1-42, 1955.

Gao Y., Lu Y., Wu M.Q. et al.: Ability to remove $\mathrm{Na}^{+}$and retain $\mathrm{K}^{+}$correlates with salt tolerance in two maize inbred lines seedlings. - Front. Plant Sci. 7: 1716, 2016.

Genty B., Briantais J.M., Baker N.R.: The relationship between the quantum yield of photosynthetic electron transport and quenching of chlorophyll fluorescence. - BBA-Gen. Subjects 990: 87-92, 1989.

Goltsev V., Kalaji M.H., Paunov M. et al: Using variable chlorophyll fluorescence for evaluation of physiological state photosynthetic apparatus plants. - Rus. J. Plant Physl+ 63: 869-893, 2016.

Gu M.F., Li N., Shao T.Y. et al.: Accumulation capacity of ions in cabbage (Brassica oleracea L.) supplied with sea water. Plant Soil Environ. 62: 314-320, 2016.

Iqbal N., Ashraf M., Ashraf M.Y.: Glycinebetaine, an osmolyte of interest to improve water stress tolerance in sunflower (Helianthus annuus L.): water relations and yield. - S. Afr. J. Bot. 74: 274-281, 2008.

Kalaji H.M., Govindjee, Bosa K. et al.: Effects of salt stress on photosystem II efficiency and $\mathrm{CO}_{2}$ assimilation of two Syrian barley landraces. - Environ. Exp. Bot. 73: 64-72, 2011. 
Kalaji H.M., Rastogi A., Živčák M. et al.: Prompt chlorophyll fluorescence as a tool for crop phenotyping: an example of barley landraces exposed to various abiotic stress factors. Photosynthetica 56: 953-961, 2018.

Kan X., Ren J., Chen T. et al.: Effects of salinity on photosynthesis in maize probed by prompt fluorescence, delayed fluorescence and P700 signals. - Environ. Exp. Bot. 140: 56-64, 2017.

Koyro H.W., Hussain T., Huchzermeyer B., Khan M.A.: Photosynthetic and growth responses of a perennial halophytic grass Panicum turgidum to increasing $\mathrm{NaCl}$ concentrations. Environ. Exp. Bot. 91: 22-29, 2013.

Krause G.H., Weis E.: Chlorophyll fluorescence and photosynthesis: the basics. - Annu. Rev. Plant Phys. 42: 313349, 1991.

Kwon T.R., Siddiqui Z.S., Harris P.J.C.: Effect of supplemental $\mathrm{Ca}^{++}$on ion accumulation, transport and plant growth of salt sensitive Brassica rapa landraces. - J. Plant Nutr. 32: 644667, 2009.

Lutts S., Kinet J.M., Bouharmont J.: NaCl-induced senescence in leaves of rice (Oryza sativa L.) cultivars differing in salinity resistance. - Ann. Bot 78: 389-398, 1996.

Maxwell K., Johnson G.N.: Chlorophyll fluorescence: a practical guide. - J. Exp. Bot. 51: 659-668, 2000.

Mehta P., Jajoo A., Mathur S., Bharti S.: Chlorophyll $a$ fluorescence study revealing effects of high salt stress on Photosystem II in wheat leaves. - Plant Physiol. Bioch. 48: 16-20, 2010.

Murkowski A.: Effects of some stress factors on chlorophyll luminescence in the photosynthetic apparatus of crop plants. Habilitation thesis. - Acta Agrophys. 61: 3-158, 2002. [In Polish with English summary]

Netondo G.W., Onyango J.C., Beck E.: Sorghum and salinity: II. Gas exchange and chlorophyll fluorescence of sorghum under salt stress. - Crop Sci. 44: 806-811, 2004.

Nxele X., Klein A., Ndimba B.K.: Drought and salinity stress alters ROS accumulation, water retention, and osmolyte content in sorghum plants. - S. Afr. J. Bot. 108: 261-266, 2017.

Oukarroum A., Bussotti F., Goltsev V., Kalaji H.M.: Correlation between reactive oxygen species production and photochemistry of photosystems I and II in Lemna gibba plants under salt stress. - Environ. Exp. Bot. 109: 80-88, 2015.

Oukarroum A., Schansker G., Strasser R.J.: Drought stress effects on photosystem-I-content and photosystem II thermotolerance analysed using $\mathrm{Chl} a$ fluorescence kinetics in barley varieties differing in their drought tolerance. - Physiol. Plantarum 137: 188-199, 2009.

Papageorgiou G.C., Govindjee: Chlorophyll $a$ Fluorescence.ASignature of Photosynthesis. Pp. 818. Springer, Dordrecht 2004.

Saensee K., Machikowa T., Muangsan N.: Comparative performance of sunflower synthetic varieties under drought stress. - Int. J. Agric. Biol. 14: 929-934, 2012.

Stirbet A., Govindjee: On the relation between the Kautsky effect (chlorophyll $a$ fluorescence induction) and Photosystem II: Basics and applications of the OJIP fluorescence transient. J. Photoch. Photobio. B 104: 236-257, 2011.

Strasser R.J., Srivastava A., Tsimilli-Michael M.: Analysis of the chlorophyll $a$ fluorescence transient. - In: Papageorgiou G.C., Govindjee (ed.): Chlorophyll $a$ Fluorescence. A Signature of Photosynthesis. Pp. 321-362. Springer, Dordrecht 2004.

Strasser R.J., Srivastava A., Tsimilli-Michael M.: The fluorescence transient as a tool to characterize and screen photosynthetic samples. - In: Yunus M., Pathre U., Mohanty P. (ed.): Probing Photosynthesis: Mechanisms, Regulation and Adaptation. Pp. 445-483. Taylor and Francis, London 2000.

Strasser R.J., Tsimilli-Michael M., Qiang S., Goltsev V.: Simultaneous in vivo recording of prompt and delayed fluorescence and 820-nm reflection changes during drying and after rehydration of the resurrection plant Haberlea rhodopensis. - BBA-Bioenergetics 1797: 1313-1326, 2010.

Sun Z.W., Ren L.K., Fan J.W.: Salt response of photosynthetic electron transport system in wheat cultivars with contrasting tolerance. - Plant Soil Environ. 11: 515-521, 2016.

Takahashi S., Murata N.: Interruption of the Calvin cycle inhibits the repair of photosystem II from photodamage. - BBABioenergetics 1708: 352-361, 2005.

Tang X., Mu X., Shao H. et al.: Global plant-responding mechanisms to salt stress: physiological and molecular levels and implications in biotechnology. - Crit. Rev. Biotechnol. 35: 425-437, 2015.

Umar M., Siddiqui Z.: Physiological performance of sunflower genotypes under combined salt and drought stress environment. - Acta Bot. Croat. 77: 36-44, 2018.

Vieira Santos C.L., Campos A., Azevedo H., Caldeira G.: In situ and in vitro senescence induced by $\mathrm{KCl}$ stress: Nutritional imbalance, lipid peroxidation and antioxidant metabolism. J. Exp. Bot. 52: 351-360, 2001.

Wang W., Vinocur B., Altman A.: Plant responses to drought, salinity and extreme temperatures: towards genetic engineering for stress tolerance. - Planta 218: 1-14, 2003.

Wu X.X., Ding H.D., Chen J.L. et al.: Attenuation of saltinduced changes in photosynthesis by exogenous nitric oxide in tomato (Lycopersicon esculentum Mill. L.) seedlings. - Afr. J. Biotechnol. 9: 7837-7846, 2010.

Yan K., Shao H., Shao C.: Physiological adaptive mechanisms of plants grown in saline soil and implications for sustainable saline agriculture in coastal zone. - Acta Physiol. Plant. 35: 2867-2878, 2013.

Zaghdoudi M., Msilini N., Govindachary S. et al.: Inhibition of photosystems I and II activities in salt stress-exposed Fenugreek (Trigonella foenum graecum). - J. Photoch. Photobio. B 105: 14-20, 2011.

Zivcak M., Brestic M., Balatova Z.: Photosynthetic electron transport and specific photoprotective responses in wheat leaves under drought stress. - Photosynth. Res. 117: 529-546, 2013.

(C) The authors. This is an open access article distributed under the terms of the Creative Commons BY-NC-ND Licence. 